\title{
Influence of formulation of elemental $S$ fertilizer on yield, quality and $S$ uptake of canola seed
}

\author{
S. S. Malhi ${ }^{1}$, E. D. Solberg ${ }^{2}$ and M. Nyborg ${ }^{3}$ \\ ${ }^{1}$ Agriculture and Agri-Food Canada, P.O. Box 1240, Melfort, Saskatchewan S0E 1A0; \\ ${ }^{2}$ Alberta Agriculture, Food and Rural Development, Edmonton, Alberta; and \\ ${ }^{3}$ Department of Renewable Resources, University of Alberta, Edmonton, Alberta
}

\section{BACKGROUND}

- Plants use only the sulphate form of S.

- Now, there are many commercial fertilizers that contain $\mathrm{S}$ in elemental form and effectiveness of these fertilizers depends on the rate at which $\mathrm{S}$ is oxidized to sulphate-S in soil for plant uptake.

- Rate of S oxidation in elemental S fertilizers to plant available sulphate-S depends on factors that affect microbial activity such as soil moisture, temperature, aeration and size of fertilizer granules.

- Deficiency of S in canola can be readily or effectively prevented or eliminated by applying sulphate-S fertilizers.

- In a number of field studies, canola has been found to produce lower seed yield with elemental $\mathrm{S}$ fertilizers than with sulphate-S fertilizers on S-deficient soils, particularly in the first year of application and especially with spring application at seeding time.

- In most of the previous studies, granular elemental $\mathrm{S}$ and sulphate-S fertilizers were used.

- There is little information on the influence of formulation of elemental $\mathrm{S}$ on seed yield and $\mathrm{S}$ uptake of canola in the Parkland region of western Canada, where canola is a major cash crop and many agricultural soils are deficient or potentially deficient in plant-available $\mathrm{S}$ for optimum seed yield.

\section{OBJECTIVE}

- The objective of this study was to determine the influence of formulation of elemental S fertilizers on yield, oil, protein and S concentration, S uptake, percent recovery of applied $\mathrm{S}$ and $\mathrm{N}$ uptake in seed of canola grown on $\mathrm{S}$-deficient soils.

\section{MATERIALS AND METHODS}

- Three field experiments were conducted on S-deficient Gray and Dark Gray Luvisol soils (Typic Cryoboralf) in Saskatchewan and Alberta in 2000 and 2001.

- Experiment 1 was conducted in 2000 and 2001, and same treatment was imposed on a given plot in both years. Experiment 2 was carried out in 2000 near Legal, Alberta. 
- In Experiments 1 and 2, treatments included five elemental S fertilizers (ES-99 granular, ES-95 granular, ES-90 granular, Biosul-90 granular, and Biosul-50 suspension), a sulphate-S fertilizer (potassium sulphate) and a zero-S control.

- Experiment 3 was conducted near Canwood, Saskatchewan, and had eight elemental S fertilizers (ES-99 granular, ES-95 granular, ES-90 granular, Biosul90 granular, Biosul-50 suspension, Lab fine ES-99.5 powder, ES Settle-47 powder and ES SPB571-85.8 powder), a granular fertilizer containing $21.7 \%$ elemental S and 18.7\% sulphate-S (Agrium Plus), a granular fertilizer blend of ES-90 and ammonium sulphate (1:1), a sulphate-S fertilizer (ammonium sulphate) and a zero-S control.

- ES-99 granular and ES Settle-47 powder were obtained from Shell Global Solution, ES-95 granular from Fernz SulFer Inc., ES-90 granular from Tiger Industries, Biosul-90 granular and Biosul-50 suspension from New Paradigms, ES SPB571-85.8 powder from Alberta Research Council, and Agrium Plus from Agrium.

- Each treatment was replicated four times in a randomized complete block design. All plots received a blanket annual application of N, P and K fertilizers 3-5 days prior to seeding in spring, and were tilled once to incorporate the fertilizers into the soil.

- Crop canola (Brassica napus L. cv. A4573 at Porcupine Plain, and cv. Invigor 2663 at Legal and Canwood) was seeded in mid to late May at a seed rate of $9 \mathrm{~kg}$ $\mathrm{ha}^{-1}$.

- The $\mathrm{S}$ fertilizers were surface-broadcast or sprayed at 15 and $30 \mathrm{~kg} \mathrm{~S}^{-1}$ rates within 2-3 days after sowing in spring.

- Data were recorded on yield, concentration of oil, protein and S, and uptake of S and $\mathrm{N}$ in seed.

\section{RESULTS}

- Canola plants in the zero-S treatment showed S deficiency in the growing season, and seed yield increased with sulphate-S fertilizer by 21.8, 1.4, and 3.6 times in Experiment 1, 2, and 3, respectively.

- There was little effect of S fertilizer on protein concentration in seed. Biosul-50 suspension in all experiments and powder forms of elemental $\mathrm{S}$ fertilizers, used only in Experiment 3, were almost as effective as sulphate-S fertilizers.

- In all experiments, granular elemental $\mathrm{S}$ fertilizers had no or only very small effect on seed yield, S uptake, \% recovery of applied S, N uptake, oil concentration, $\mathrm{S}$ concentration and protein concentration of canola seed in first year of application.

- In second year of Experiment 1, granular elemental $\mathrm{S}$ fertilizers tended to increase seed yield, $\mathrm{S}$ uptake, $\mathrm{N}$ uptake, oil concentration, and $\mathrm{S}$ concentration of canola seed, but none of them produced seed yield or improved other parameters of canola seed comparable to the sulphate-S and elemental S powder or suspension fertilizers. 


\section{CONCLUSIONS}

- Seed yield, N uptake and S uptake of canola seed were very low in the absence of $\mathrm{S}$ fertilization on S-deficient soils.

- There was a marked increase in seed yield, $\mathrm{N}$ uptake and $\mathrm{S}$ uptake with granular sulphate-S and suspension or powder elemental $\mathrm{S}$ fertilizers.

- Increase in seed yield, $\mathrm{N}$ uptake and $\mathrm{S}$ uptake with increasing rate of $\mathrm{S}$ application was dependent on the severity of S deficiency.

- Granular elemental S fertilizers were not effective in correcting S deficiency in canola in the first year of application.

- Even after two annual applications in Experiment 1, seed yield, $\mathrm{N}$ uptake, $\mathrm{S}$ uptake, \% recovery of applied $\mathrm{S}$ and oil concentration in canola seed on Sdeficient soils were much less with granular elemental $\mathrm{S}$ fertilizers compared to the sulphate-S fertilizers indicating that granular elemental $\mathrm{S}$ fertilizers corrected S deficiency partially only.

- Seed yield, N uptake, S uptake and \% recovery of applied S in canola seed with surface application of suspension and powder formulations of elemental $\mathrm{S}$ fertilizers were similar to sulphate-S fertilizer, and were more than granular $S$ elemental S fertilizers.

- The findings demonstrate that on S-deficient soils granular elemental S fertilizers are less effective in increasing seed yield and quality of canola than sulphate-S fertilizer, but $\mathrm{S}$ deficiency in canola can be prevented by broadcast/spread surface-application of elemental $\mathrm{S}$ fertilizers that contain $\mathrm{S}$ particles in suspension or powder formulation producing seed yield comparable to sulphate-S fertilizer.

- Dispersion of elemental S particles from granular elemental S fertilizers in soil to enhance microbial oxidation of elemental $S$ particles to sulphate-S in soil was considered as the major problem for lack of effectiveness of granular S fertilizers.

\section{ACKNOWLEDGEMENTS}

- The authors thank New Paradigm (Gas Processing), Calgary, Alberta for financial assistance, and Z. Zhang, D. Leach, K. Fidyk and K. Falk-Hemstad for technical help. 


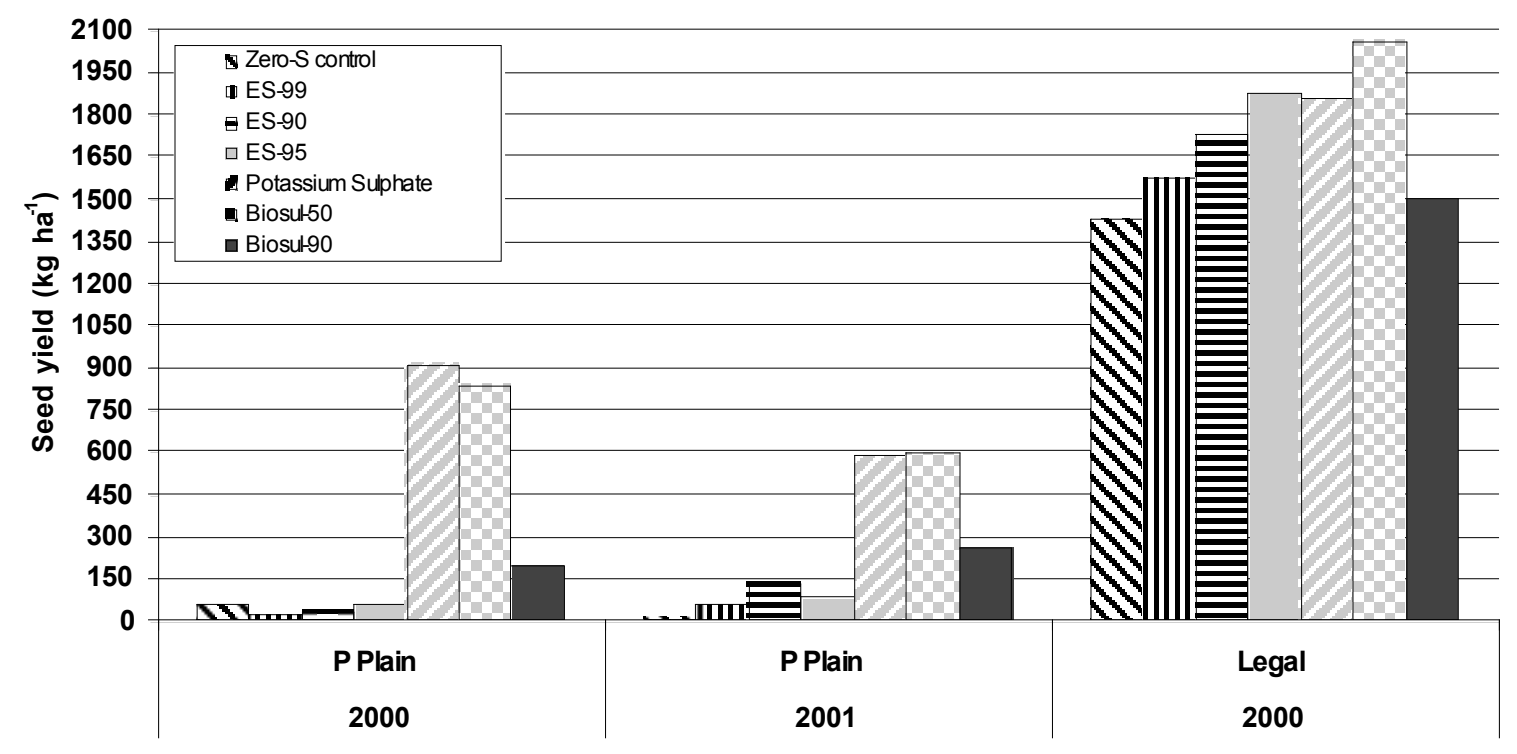

Figure 1. Seed yield of canola from various $S$ fertilizers applied at two rates (15 and 30 $\mathrm{kg} \mathrm{S} \mathrm{ha}^{-1}$ ) at Porcupine Plain (Experiment 1) and Legal (Experiment 2) in 2000 (averaged across the two $\mathrm{S}$ rates).

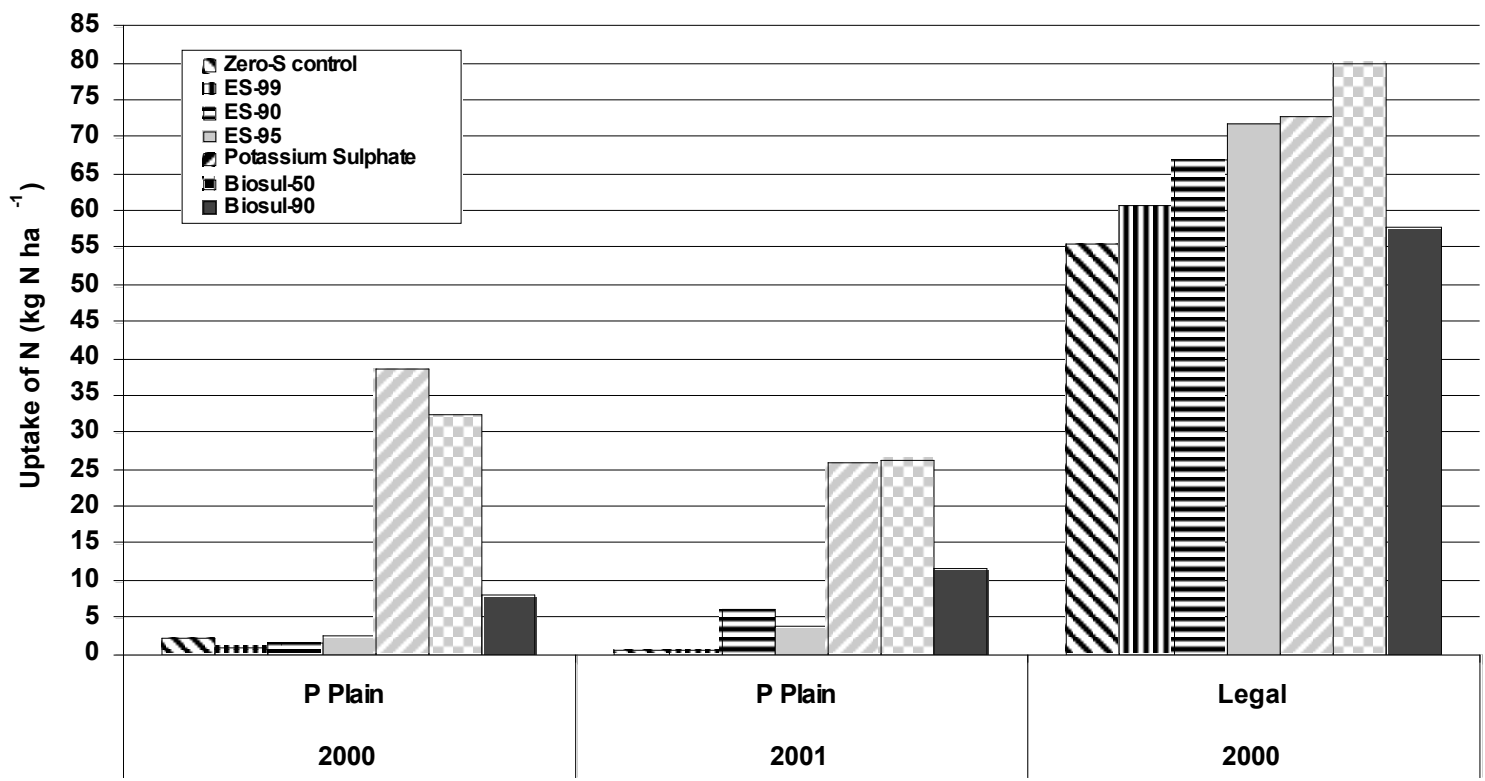

Figure 2. Nitrogen uptake in canola seed from various $\mathrm{S}$ fertilizers applied at two rates (15 and $30 \mathrm{~kg} \mathrm{~S} \mathrm{ha}^{-1}$ ) at Porcupine Plain (Experiment 1) and Legal (Experiment 2) in 2000 (averaged across the two $\mathrm{S}$ rates). 


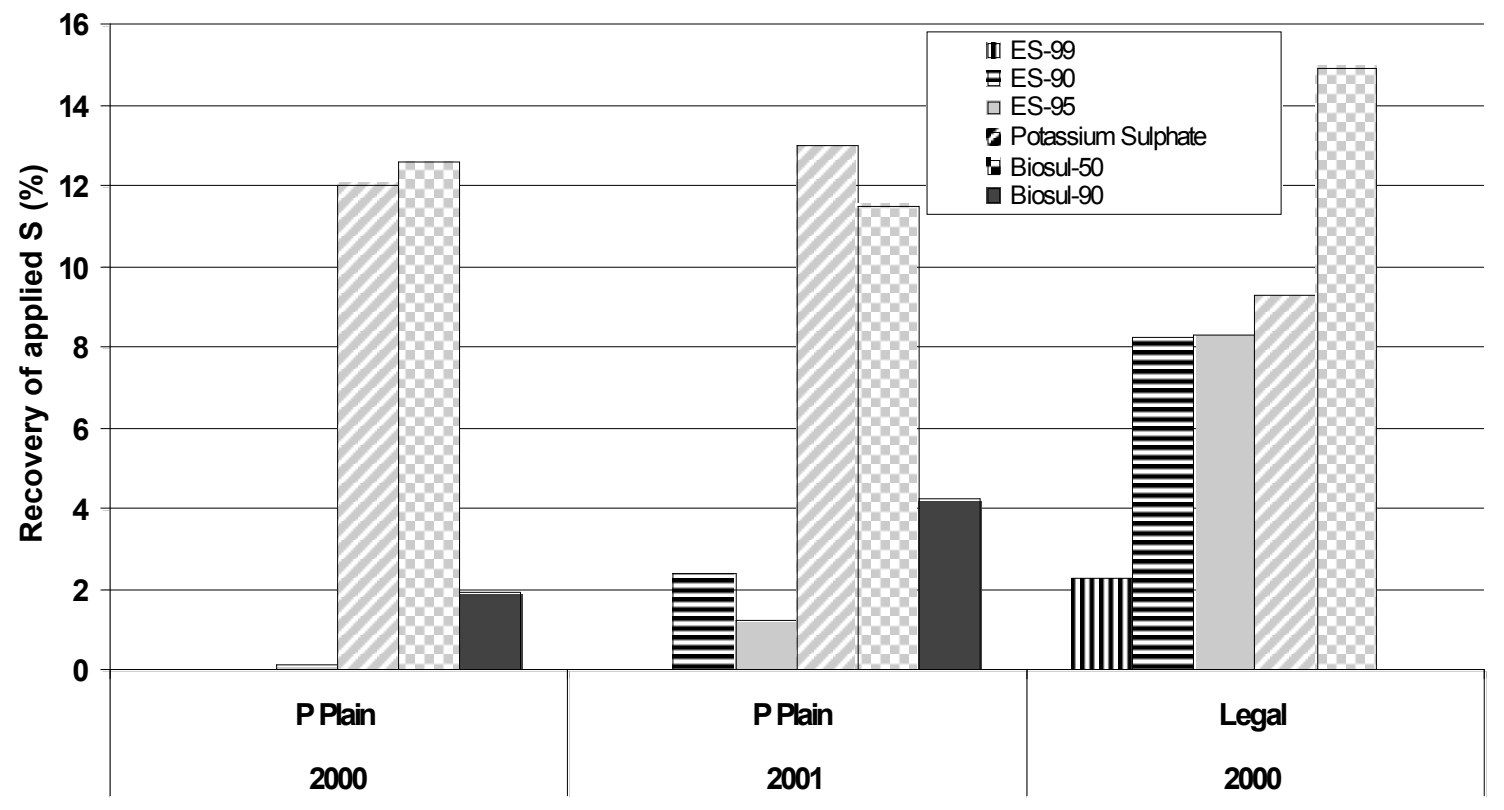

Figure 3. Recovery of applied $\mathrm{S}$ fertilizer in canola seed from various $\mathrm{S}$ fertilizers applied at two rates (15 and $30 \mathrm{~kg} \mathrm{~S} \mathrm{ha}^{-1}$ ) at Porcupine Plain (Experiment 1) and Legal (Experiment 2) in 2000 (averaged across the two $\mathrm{S}$ rates).

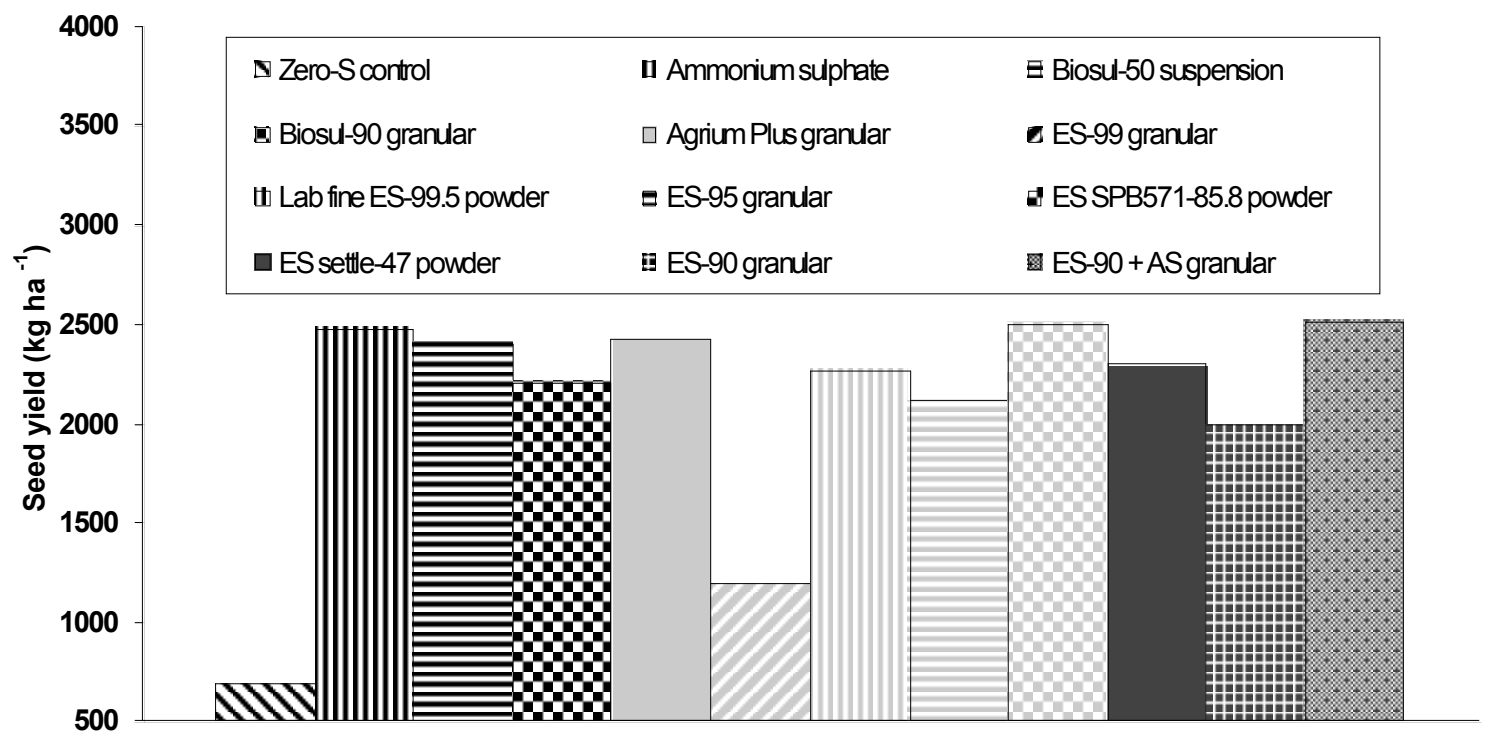

Figure 4. Seed yield of canola from various $S$ fertilizers applied at two rates (15 and 30 $\mathrm{kg} \mathrm{S} \mathrm{ha}{ }^{-1}$ ) at Canwood (Experiment 3) in Northwestern Saskatchewan in 2001 (averaged across the two $\mathrm{S}$ rates). 


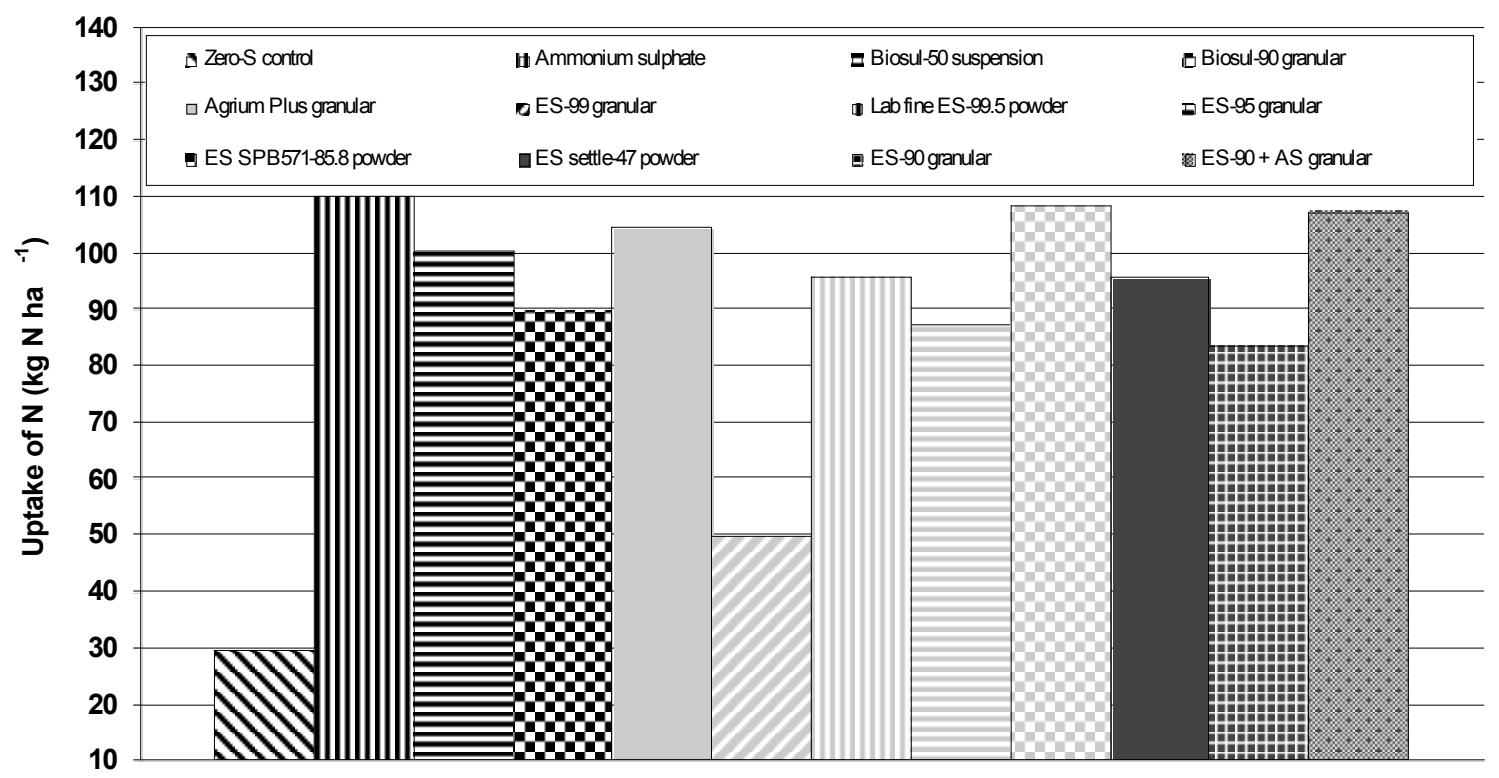

Figure 5. Nitrogen uptake in canola seed from various $\mathrm{S}$ fertilizers applied at two rates (15 and $30 \mathrm{~kg} \mathrm{~S} \mathrm{ha}^{-1}$ ) at Canwood (Experiment 3) in Northwestern Saskatchewan in 2001 (averaged across the two $\mathrm{S}$ rates).

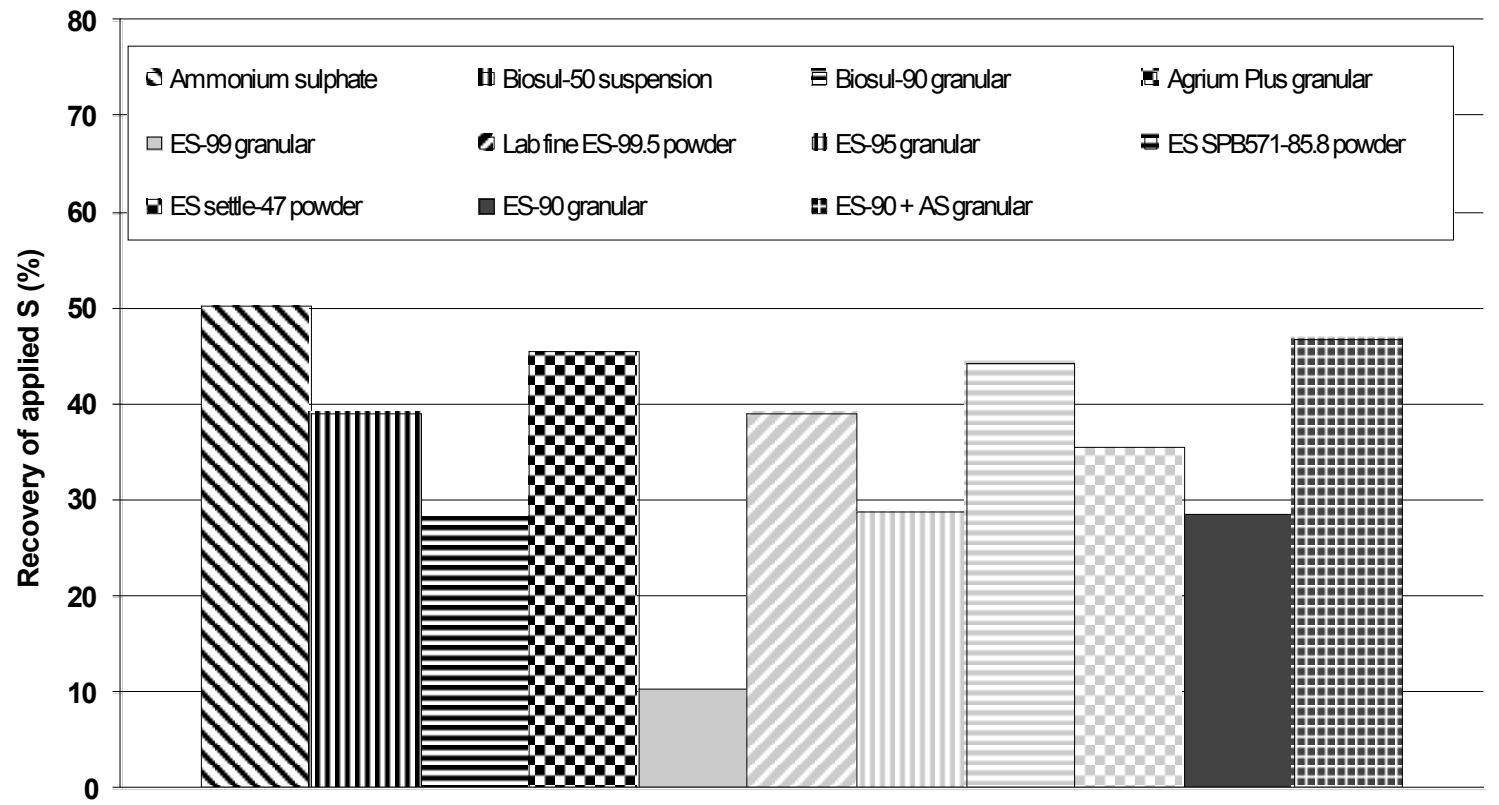

Figure 6. Recovery of applied $\mathrm{S}$ in canola seed from various $\mathrm{S}$ fertilizers applied at two rates (15 and $30 \mathrm{~kg} \mathrm{~S} h a^{-1}$ ) at Canwood (Experiment 3) in Northwestern Saskatchewan in 2001 (averaged across the two $\mathrm{S}$ rates). 